\title{
JOURNAL.RU
}

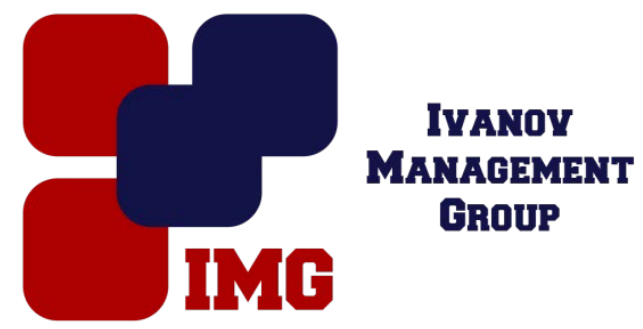

Чернопятов А.М., Сидоркина Е.В. Сургутский государственный педагогический университет Сургут, Россия

doi: 10.18411/lj-31-01-2017-2-10

idsp 000001:lj-31-01-2017-2-10

\section{Информационная безопасность в деятельности организаций на современном этапе}

\section{Аннотация}

В статье рассматриваются вопросы в области информационной безопасности. В рыночных условиях информационная безопасность становится наиболее актуальной для деятельности предприятий. Умение правильно ставить данный вопрос позволит более устойчиво работать организациям на рынке.

Ключевые слова: безопасность, информация, ресурсы, интеллектуальные, задачи, творчество, сфера, рынок, участники, собственность, организация, защита.

\section{Abstract}

The article discusses issues in the field of information security. In market terms, information security is becoming more relevant for enterprises. The ability to put this question would allow for a more sustainable organizations in the market.

Keywords: security, information, resources, intellectual challenges, creativity, sphere, market, participants, property, organization, protection.

Организация информационной безопасности в области интеллектуальных ресурсов всегда являлась одной из основных задач для учреждений, организаций и предприятий. Государство, уделяет особое внимание данному направлению, и систематически, вносит различные изменения в законодательную базу, или вовсе меняя полностью их. На глобальном уровне постоянно ужесточаются правила игры в области интеллектуальной собственности и претензии предъявляются уже не только к отдельным личностям, а и к государствам.

Под интеллектуальной собственностью принято понимать установленное законом временное право, а также личные неимущественные права авторов на результат интеллектуальной деятельности или средства индивидуализации. Нормативно-правовые акты, которые регламентируют права на интеллектуальную собственность, устанавливают монополию на определенные формы использования результатов интеллектуальной, творческой деятельности, которые, таким образом, могут использоваться другими лицами лишь с разрешения первых. 
В информационную безопасность входит защита интеллектуальной собственности, а также жизненно важных интересов личности, общества и государства на сбалансированной основе в информационной сфере от внутренних и внешних угроз.

"Рынок предъявляет жесткие требования к созданию высокотехнологичного производства во всех сферах народного хозяйства"[2]. На каждом предприятии, особенно высокотехнологичном, одним из важнейших путей достижения его максимальной эффективности является усовершенствование такой системы, как организация и обеспечение надежной системы безопасности.

От того, каким образом в организации выстроена работа данной системы, зависит множество аспектов в достижении основных целей предприятия. Результатом качественной работы предприятия в направлении безопасности является стабильность и гармоничность ее деятельности, и, как следствие, стабильный рост такого показателя, как оптимизация прибыльности предприятия.

На современном этапе стало массовым процессом заимствования интеллектуальной собственности (научные знания, методики, программы, и технологии) сотрудниками организаций, работающими в различных структурах и что особенно важно это относится и к государственному уровню. Дополнением к этому идут целенаправленные действия по хэдхантингу, подкупу сотрудников предприятий-конкурентов, с целью завладения секретами их производственной и коммерческой деятельности.

Развитие промышленного шпионажа предполагает использование в своем арсенале:

- новейшие достижения электроники;

- -личное тайное наблюдение;

- -подкуп сотрудников конкурентов или заинтересованных объектов;

- -применение шантажа к объектам внимания;

- -криминальный подход и прочее.

Для достижения поставленных целей идет большая «тайная война». В Российской Федерации, начиная с начала 90-х годов в условиях перехода на рыночные отношения и переориентации предприятий на самофинансирование и самоокупаемость появилась проблема по безопасности в области сохранности сохранения ноу-хау, коммерческой тайны и много другого "данный механизм находится перманентном реформировании"[4].

Отечественная и особенно зарубежная практика показывает, что основная тяжесть и роль в обеспечении безопасности ложится на сами предприятия, а не на государственные структуры. Государственные структуры создают свои службы безопасности, а коммерческие организация свои.

Рассмотрим понятия «безопасность» и «информационная безопасность» для более подробного понимания важности процесса защиты информации.

В законодательных актах (Федеральный закон "О безопасности" от 28.12.2010 N 390-Ф3 (действующая редакция, 2016) в п.4, ст.3 под безопасностью понимает «разработку и применение комплекса оперативных и долговременных мер по выявлению, предупреждению и устранению угроз безопасности, локализации и нейтрализации последствий их проявления». 
«Информационная безопасность - это защищенность информации и поддерживающей инфраструктуры от случайных или преднамеренных воздействий естественного или искусственного характера, чреватых нанесением ущерба владельцам или пользователям информации и поддерживающей инфраструктуры»[1].

Цель защиты информационной безопасности - это сведение к минимальным потерям в управлении информационной системы, вызванных нарушением или разрушением целостности определенных данных, например недоступности информации или их конфиденциальности для заинтересованных лиц. задач[7]:

Для достижения цели требуется реализация следующих поставленных

- «выявление угроз для стабильности и развития предприятия и выработка мер по их противодействию;

- обеспечение защиты технологических процессов;

- реализация мер противодействия всех видов шпионажа (промышленного, научно-технического, экономического и т.д.);

- своевременное информирование руководства предприятия о фактах нарушения законодательства со стороны государственных и муниципальных органов, коммерческих и некоммерческих организаций, затрагивающих интересы предприятия;

- предупреждение переманивания сотрудников предприятия, обладающих конфиденциальной информацией;

- всестороннее изучение деловых партнеров;

- своевременное выявление и адекватное реагирование на дезинформационные мероприятия;

- разработка и совершенствование локальных правовых актов, направленных на обеспечение безопасности предприятия;

- реализация мер по защите коммерческой и иной информации;

- организация мероприятий по противодействию недобросовестной конкуренции;

- обеспечение защиты всех видов ресурсов предприятия;

- реализация мер по защите интеллектуальной собственности;

- организация и проведение мер по предотвращению чрезвычайных ситуаций;

- выявление негативных тенденций среди персонала предприятия, информирование о них руководства предприятия и разработка соответствующих рекомендаций;

- организация взаимодействия с правоохранительными и контрольными органами в целях предупреждения и пресечения правонарушений, направленных против интересов предприятия;

- разработка и реализация мер по предупреждению угроз физической безопасности имуществу предприятия и его персоналу; 
- возмещение материального и морального ущерба, нанесенного предприятию в результате неправомерных действий организаций и отдельных физических лиц».

В своей работе Чернопятов А.М. говорит: "В основе стратегии и политики развития конкурентоспособности экономики России должна лежать государственная стратегия экономической безопасности как цементирующего и монолитного фундамента экономической безопасности страны для реализации ее конкурентных преимуществ"[3]. Чтобы выполнить в общем плане такой подход, необходимо на уровне предприятий более жестко и четко разрабатывать такие стратегии.

Система безопасности предприятия включает в себя ряд следующих подсистем:

Экономическая безопасность предприятия (ЭБП) - состояние наиболее эффективного использования всех видов ресурсов в целях предотвращения (нейтрализации, ликвидации) угроз и обеспечения стабильного функционирования предприятия в условиях рыночной экономики."Среди экономических проблем, как составляющих экономики, предприятие занимает особое место. С сущностью, экономической природой предприятия, связывается нахождение ответов на основополагающие вопросы экономики"[5].

ЭБП характеризуется совокупностью качественных и количественных показателей, важнейшим среди которых является уровень экономической безопасности[8].

Для того чтобы достичь наиболее высокого уровня экономической безопасности, предприятие должно следить за обеспечением максимальной безопасности основных функциональных составляющих системы ЭБП.

Функциональные составляющие ЭБП - это совокупность основных направлений его экономической безопасности, существенно отличающихся друг от друга по своему содержанию.

Выделяют следующие функциональные составляющие ЭБП:

- финансовую;

- интеллектуальную и кадровую;

- техногенную;

- политико-правовую;

- экологическую;

- информационную;

- силовую.

Следует отметить, что вышеуказанные подсистемы второго уровня могут включать в себя подсистемы третьего уровня. Например, подсистемами экономической безопасности могут быть - финансовая, коммерческая, имущественная, а также другие подсистемы безопасности.

Кроме этого, сами подсистемы не разделены между собой непроходимой границей, поскольку они настолько взаимосвязаны друг с другом, что в органическом единстве образуют единую систему безопасности предприятия. Разделение же единой системы безопасности предприятия на подсистемы второго и третьего уровня производится из методических соображений, поскольку это позволяет более детально изучить все его элементы. 
Для обеспечения своей экономической безопасности предприятие использует совокупность корпоративных ресурсов.

Корпоративные ресурсы - факторы бизнеса, используемые владельцами и менеджерами предприятия для выполнения целей бизнеса.

Среди них выделим:

- peсурс капитала. Капитал организации в сочетании с заемными финансовыми средствами является главной артерией предприятия и позволяет приобретать и поддерживать жизненный цикл организации;

- pecyрс персонала. Штатный персонал организации с их знаниями, опытом и навыками являются основным звеном, соединяющим воедино все факторы данного бизнеса, обеспечивающим проведение в жизнь идеологии бизнеса, а также достижение целей бизнеса;

- peсурс информации и технологии. Информация, касающаяся всех сторон деятельности предприятия, является в настоящее время наиболее ценным и дорогостоящим из ресурсов предприятия. Именно информация об изменении политической, социальной, экономической и экологической ситуации, рынков предприятия, научно-техническая и технологическая информация, know-how, касающиеся каких-либо аспектов данного бизнеса, новое в методах организации и управления бизнесом позволяют предприятию адекватно реагировать на любые изменения внешней среды бизнеса, эффективно планировать и осуществлять свою хозяйственную деятельность;

- pесурс техники и оборудования. На основе имеющихся финансовых, информационно-технологических и кадровых возможностей предприятие приобретает оборудование;

- peсурс прав. Использование этого ресурса позволяет предприятию приобщиться к передовым технологическим разработкам, не проводя собственных дорогостоящих научных исследований, а также получить доступ к необщедоступным возможностям развития бизнеса.

Обеспечение экономической безопасности предприятия - это процесс реализации функциональных составляющих экономической безопасности с целью предотвращения возможных ущербов и достижения максимального уровня экономической безопасности в настоящее время и в будущем.

В современных условиях процесс успешного функционирования и экономического развития российских предприятий во многом зависит от совершенствования их деятельности в области обеспечения экономической безопасности. Следует заметить, что сегодня не все руководители предприятий готовы в полной мере оценить важность создания надежной системы экономической безопасности. Экономическая безопасность предприятия — это состояние его защищенности от негативного влияния внешних и внутренних угроз, дестабилизирующих факторов, при которых достигается устойчивая реализация главных коммерческих интересов и целей уставной деятельности.

С учетом перечисленных мер, условий конкурентной борьбы, специфики бизнеса предприятия строится его система экономической безопасности. Необходимо отметить, что система экономической безопасности каждой компании также сугубо индивидуальна. Ее полнота и действенность во многом 
зависят от имеющейся в государстве законодательной базы, выделяемых руководителем предприятия материально-технических и финансовых ресурсов, понимания каждым из сотрудников важности обеспечения безопасности бизнеса, a также от знаний и практического опыта начальника системы экономической безопасности, непосредственно занимающегося построением и поддержанием в «рабочем состоянии» самой системы.

Обеспечение безопасности организации достаточно часто недооценивается ее участниками (акционерами) и руководителем организации. Нередко это приводит к очень серьезным последствиям, начиная с краж имущества и заканчивая захватами юридического лица целиком. Тогда как ряд достаточно простых, но проводимых в комплексе мероприятий может серьезно снизить данные риски. "Структурировать полученную информацию и внедрить"[6]. Прежде чем определять список этих мероприятий, необходимо оценить реальные угрозы. Их принято разделять на два вида:

Внешние угрозы. К ним относятся:

- деятельность недобросовестных конкурентов, направленная на подрыв деловой репутации организации, хищения -принадлежащих ей ноу-хау, коммерческой тайны;

- действия рейдерских компаний или отдельных лиц, направленные на перехват управления организации или на захват ее имущества;

- гринмейл (greenmail, производное от green - «деньги» и blackmail «шантаж»), то есть корпоративный шантаж -в отношении организации; действия физических лиц из личной неприязни к юридическому лицу, его руководителям или сотрудникам, направленные на причинение ущерба материальным ценностям общества или его деловой репутации;

- неправомерные действия работников государственных -силовых органов и т.Д.

К внутренним угрозам относятся: нарушения работниками трудовой дисциплины; правонарушения работников, направленные на причинение материального ущерба организации или подрыв ее деловой репутации; «некачественный» подбор персонала и др.[9].

Надежность и эффективность системы безопасности предприятия оценивается на основе одного критерия - степени отсутствия или наличия нанесенного ему материального ущерба и морального вреда.

Содержание этого критерия раскрывается через ряд показателей:

- недопущение фактов утечки конфиденциальных сведений;

- предупреждение или пресечение противоправных действий со стороны персонала предприятия, его посетителей, клиентов;

- сохранность имущества и интеллектуальной собственности предприятия;

- предупреждение чрезвычайных ситуаций;

- пресечение насильственных преступлений в отношении отдельных (специально выделенных) сотрудников и групп сотрудников предприятия;

- своевременное выявление и пресечение попыток несанкционированного проникновения на охраняемые объекты предприятия. 
Подводя итоги, можно сказать, что в современных условиях невозможно успешно развивать любую деятельность без современных средств безопасности и комплексного подхода по решению этой проблемы. Задача руководителей организаций, учреждения и предприятий своевременно решать сложившиеся вопросы в области интеллектуальной тематики на комплексной основе.

\section{Литература}

1. А. Н. Асаул. Организация предпринимательской деятельности. Учебник. СПб.: АНО ИПЭВ, 2009. 336c.

2. Чернопятов А.М. Роль институтов государства в организации национальной хозяйственно системы// Транспортное дело России. -2016.-№1.-с.87.

3. Чернопятов А.М. Экономическая безопасность страны в свете глобализации экономики// Транспортное дело России. -2015.-№3.-с.18.

4. Чернопятов А.М. Функциональная составляющая в области государственного регулирования предпринимательства// Транспортное дело России. -2014.-№3.-с.78.

5. Чернопятов А.М. Место предприятия в институционализации производственнохозяйственного сектора// Транспортное дело России. -2011.-№6.-с.50.

6. Чернопятов А.М.Бенчмаркетинг: Учебное пособие для студентов высш. учеб. заведений.-С: Издательство ООО "Винчера", 2014.-с.227.

7. http://datasolution.ru/sistema-bezopasnosti-predpriyatiya-2/

8. http://www.profiz.ru/se/12_2004/952/ («Справочник экономиста» №12 2004 / Разное)

9. $\quad$ http://delo-press.ru/articles.php?n=6410 